Revista Crítica de Ciências Sociais

de Ciênncias Sociais $\quad 76 \mid 2006$

Estudos queer. Identidades, contextos e acção

colectiva

\title{
Butler, Judith, Undoing Gender
}

\section{Anabela Rocha}

\section{(2) OpenEdition}

Journals

Edição electrónica

URL: http://journals.openedition.org/rccs/875

DOI: $10.4000 /$ rccs. 875

ISSN: 2182-7435

Editora

Centro de Estudos Sociais da Universidade de Coimbra

Edição impressa

Data de publição: 1 dezembro 2006

Paginação: 143-145

ISSN: 0254-1106

Refêrencia eletrónica

Anabela Rocha, «Butler, Judith, Undoing Gender », Revista Crítica de Ciências Sociais [Online], 76 | 2006, posto online no dia 01 outubro 2012, consultado o 21 setembro 2020. URL : http:// journals.openedition.org/rccs/875; DOI : https://doi.org/10.4000/rccs.875 


\section{Recensões}

\section{Binnie, Jon, The Globalization of Sexuality. London: Sage, 2004, 176 p.}

Jon Binnie tem um longo trabalho no âmbito da Geografia das Sexualidades, partilhando tal reconhecimento científico com nomes como Gill Valentine ou David Bell. Neste seu mais recente livro, Binnie retoma algumas perplexidades formuladas em The Sexual Citizen: Queer Politics and Beyond (com D. Bell, 2000) ou Pleasure Zones: Bodies, Cities, Spaces (com R. Holliday, R. Longhurst e R. Peace, 2001).

O objectivo principal de The Globalization of Sexuality consiste em dar conta da heteronormatividade dos estudos mainstream sobre globalização e contribuir para uma perspectiva queer sobre a temática. Examinando questões como "De que forma os fenómenos de nacionalismo, classe e transnacionalização interagem com as sexualidades?" e "Como é que as sexualidades constroem ou (re)produzem categorias como Estado-nação ou identidades de classe?", Binnie sublinha a centralidade da auto-reflexividade como instrumento de desconstrução crítica e elaboração de novas perspectivas queer.

Para Binnie, as teorias da globalização frequentemente omitem diferenças entre Estados-nação e dentro das fronteiras nacionais, ao que acrescem diferenças na forma como as culturas sexuais têm sido estudadas. Salienta-se aqui o carácter pioneiro dos EUA, cuja reflexão tem dominado os estudos gays e lésbicos desde sempre, resultando numa sobreposição entre discursos anti-gay e a retórica anti-americana. Binnie postula que uma forma de ultrapassar tal armadilha conceptual é valorizar a produção científica desenvolvida fora dos grandes centros hegemónicos, mediante a elaboração de um quadro teórico partilhado entre centros e periferias.

Binnie nota um fracasso genérico dos estudos gays e lésbicos em tratar o tema do nacionalismo, como se fosse mais simples (ou possível) quebrar identidades sexuais do que identidades nacionais. Tal ficará a dever-se a uma estreiteza de perspectivas associada à ausência de análises científicas de sexualidades não-ocidentais, tal como assinalado pelas teorias pós-coloniais. Neste passo, indaga-se: por que razão é o controlo das sexualidades tão fundamental nos projectos nacionalistas? Binnie acredita que a sexualidade é encarada pelo Estado-nação como ameaça porque não é facilmente controlável. Assim, o sado-masoquismo consensual entre pessoas do mesmo sexo é muitas vezes criminalizado porque desafia o monopólio do Estado sobre a violência. Da mesma forma, o uso da violação sexual enquanto arma de guerra revela que o Estado controla violentamente o sexo e a sexualidade, ilustrando igualmente a forma como a ideologia do nacionalismo é marcada pela questão da diferença sexual. Binnie prossegue questionando-se sobre até que ponto os direitos LGBT são utilizados como instrumentos de reprodução de nacionalismos específicos, investigando as possibilidades de extrapolação na aplicação de modelos conceptuais desenvolvidos num dado país. O facto de a dissidência sexual poder agir (ou ser lida enquanto agindo) como contrapoder político também é objecto de análise, reportando-se ao exemplo da Eslovénia e à forma como a queerness parece ameaçar as fronteiras nacionais. $\mathrm{O}$ autor revela cepticismo perante o que designa 
por "política de assimilacionismo da libertação gay” (p. 25), que considera ser um sinal de domesticação das sexualidades. $\mathrm{Na}$ mesma esteira, Binnie olha para o conceito de "nação queer" através das formas como a nação é imaginada no âmbito do pensamento queer, nomeadamente a) o cariz americanizado dos discursos queer (veja-se Stonewall); b) o nacionalismo percebido como hipermasculino (i.e., uniformes, disciplina, força); c) a reivindicação de mudanças legislativas baseada no que é percepcionado como característica nacional (a tolerância irlandesa ou a liberdade holandesa). Conclui-se que "a nação importa aos dissidentes sexuais” (p. 29), embora não exista nenhuma lógica essencialista na forma como a nação é construída dentro das comunidades queer. Assim, gays e lésbicas não são meras vítimas dos nacionalismos, uma vez que beneficiam activamente de políticas nacionais de reconhecimento político.

Binnie remete-nos para a importância de olhar as localidades das práticas discursivas. Uma vez que a globalização é (re)produzida de formas distintas de acordo com o contexto geográfico, Binnie sugere cautela face ao conceito "cultura gay global". $\mathrm{O}$ autor inicia então um debate presente em muitos capítulos seguintes: será que o reconhecimento de direitos LGBT constitui um marco das sociedades progressistas, espelhando um modelo evolutivo de modernidade? Considerando diferentes marcos identitários - etnia, classe e género -, Binnie detém-se na forma como cada um deles promove ou sanciona certos modelos de dissidência sexual, o que o conduz à questão "quais os modelos de sexualidade que acabam por ser vistos como autênticos?" (p. 39), seguida de uma reflexão em torno do conceito de hibridação.

Após uma forte crítica a Dennis Altman, o autor introduz um novo tópico de análise, nomeadamente o das comunidades virtuais queer e o papel do ciberespaço na construção identitária. Enquanto espaço utópico de fuga e autopercepção, o ciberespaço permite escapar dos constrangimentos diários ou do "confinamento da heterossexualidade” (p. 42). Consequentemente, é proposto um paralelo entre ciberespaços queer e turismo queer na medida em que ambos partilham um importante papel na transmissão de uma cultura sexual: a Internet permite a antevisão dos destinos turísticos futuros e o ciberespaço converteu-se no novo lugar de cruising, permitindo que desde muito cedo se experimentem vivências queer. Contudo, este espaço apresenta condicionamentos económicos resultantes do acesso à tecnologia e linguagem, desigualdades que podem sair reforçadas.

Revisitando o debate da "libra rosa", Binnie defende que cultura e economia são mutuamente constituídas e que qualquer análise deve considerar as pessoas LGBT como trabalhadoras, mais que consumidoras. Na verdade, "a riqueza gay e lésbica é um dos mitos em torno da economia rosa. [...] Uma ênfase excessiva nos consumos queer reproduz estereótipos dos queers enquanto ricos e invisibiliza o papel de gays e lésbicas enquanto produtores" (p. 55). Prossegue-se com uma reflexão sobre as implicações de classe noutros espaços queer, nomeadamente as associações LGBT.

No capítulo 5, o autor investiga os modos como as sexualidades têm sido configuradas dentro do pós-colonialismo. Perante a acusação de que o grau de desenvolvimento societal se mede em função da abertura sócio-jurídica às questões LGBT, Binnie relembra que a heteronormatividade é um produto de exportação do Ocidente para outros contextos através da colonização. Por outro lado, assinala-se uma tendência para tratar temas LGBT como se se tratasse de questões étnicas o designado queer folk, cujo perigo reside 
no silenciamento da diversidade étnica dentro da população LGBT, "solificando categorias mais do que desafiando [...] relações de poder" (p. 69). Binnie insiste numa crítica dura ao que designa por americanização dos estudos gays e lésbicos, ao ponto de identificar uma ocidentalização da política gay e lésbica reflectida na transformação dos direitos LGBT em plataformas de acesso, por exemplo, à Europa Comunitária. Tal narrativa desenvolvimentista vai de par com discursos racistas que opõem, por exemplo, o Zimbabué à Holanda ou à Dinamarca, fazendo recordar alguma da racionalidade que enformou a missão civilizadora patente nas Cruzadas. Outro conceito complexo é o "armário" ao transformar as histórias de "coming out” em passos necessários a uma identidade e cidadania sexuais bem sucedidas. Para Binnie, a moralidade do "coming out" mais não é do que uma exportação do modelo confessional proveniente do judaico-cristianismo, encerrando num lugar inferior todos/as aqueles/as que recusarem tal confissão. Acresce ainda que o conceito de "armário" não é universal, carecendo de uma análise cuidada que considere os não-ditos, em jeito de uma sociologia das ausências das sexualidades queer.
Nos capítulos seguintes, debate-se mobilidade queer (migração e turismo), sida e urbanismo, nos seus múltiplos cruzamentos com globalizações e sexualidades queer: migração enquanto processo de "saída do armário" e de experiência de uma cidadania sexual, desejo de anonimato associado aos centros urbanos, asilo político, diáspora queer, cosmopolitismo imaginado (Gay Games), cruising como intervenção democrática e mega eventos queer (Prides, Marchas, etc.).

Em suma, mais do que fornecer um enquadramento teórico acabado, Binnie sublinha a complexidade inerente a qualquer ponto de vista, defendendo a importância de valorizar o que se esconde por baixo de superfícies aparentemente lisas. Dessa forma o autor permite ao/à leitor/a a construção da sua própria posição sobre globalizações queer, ao invés de se converter num/a consumidor/a passivo/a de escolhas alheias. Neste sentido, este livro constitui uma ferramenta importante na medida em que nos facilita conhecimentos factuais ancorados num questionamento crítico e auto-reflexivo acerca dos pressupostos dominantes nos estudos gays e lésbicos.

\section{Ana Cristina Santos}

\section{Butler, Judith, Undoing Gender. New York: Routledge, 2004, 288 p.}

O conceito de "gender" de Butler (Gender Trouble, 1990) foi um forte ponto de viragem nos estudos queer uma vez que torna radicalmente claro que o género não é uma essência já feita que seria vivenciada pelos sujeitos mas sim um permanente fazer pela sua própria reiteração performativa, que poderia subverter ou não os padrões dualistas hegemónicos.

Undoing Gender tem a particularidade de reflectir radicalmente sobre os riscos que correm aqueles que desconstroem esses padrões. Trata-se de uma reflexão crítica sobre as condições duma vida vivível para todos aqueles que desconstroem o género, ao ponto de não serem mais reconhecidos como humanos (sendo este o risco mais radical), ao ponto de a vida lhes ser insuportável, pela violência sobre eles exercida, muitas vezes até à morte - sendo a morte e as condições de possibilidade do seu luto o horizonte teórico por excelência duma qualquer política do reconhecimento. Ressalvando desde logo que as diferenças na 
posição e no desejo impossibilitam qualquer universalidade ética, este livro, se bem que ancorado nas questões queer, continua o trabalho de Precarious Life: The Power of Mourning and Violence (Butler, 2004), ou seja, uma nova filosofia política do reconhecimento, centrada na sobrevivência, de inspiração hegeliana: que tudo o que é humano não nos deve ser estranho - "Que recursos devemos possuir para trazer para a comunidade humana aqueles humanos que não foram considerados parte do reconhecidamente humano? Essa é a tarefa duma teoria e prática democrática radical que procura estender as normas que suportam uma vida viável a comunidades previamente sem direitos" (p. 225). Estas novas normas terão de ser elas próprias lugar de rearticulação do humano: "Seguramente, algumas normas serão necessárias para a construção de um tal mundo, mas serão normas que ninguém possuirá, normas que terão de trabalhar não através da normalização ou da assimilação racial e étnica, mas sim tornando-se lugares colectivos de trabalho político contínuo" (p. 231).

A rearticulação do humano só pode acontecer "[...] no ponto onde os excluídos falam para e a partir dessa categoria." (p. 13). Mas não é fácil conquistar esse lugar, uma vez que, para falar a partir dele, é necessário ser já reconhecido como humano. Daí que o trabalho crítico fundamental esteja em manter a abertura da questão pelo humano: “[...] a questão que colocamos ao Outro é simples e irrespondivel: 'quem és tu?'. A resposta violenta é aquela que não pergunta, e não procura saber" (p. 35).

Central à questão da sobrevivência é a questão da vulnerabilidade diferenciada dos corpos e a da hierarquização dos lutos: "Reagir à opressão requer que entendamos que as vidas são apoiadas e mantidas diferencialmente, que há formas radicalmente diferentes de distribuição da vulnerabili- dade física humana pelo globo. Certas vidas serão altamente protegidas, e a violação das suas exigências de santidade será suficiente para mobilizar as forças da guerra. E outras vidas não encontrarão apoio tão rápido e tempestuoso e não serão sequer qualificáveis como dignas de luto" (p. 24). Quanto à questão específica da desconstrução da diferença sexual, o que Undoing Gender traz de novo é uma humildade teórica e existencial. "Tal como eu a entendo, a diferença sexual é o lugar onde uma questão relativa à relação do biológico com o cultural é posta e reposta, onde deve e pode ser posta, mas onde não pode, estritamente falando, ser respondida. Entendida como um conceito de fronteira [...]. É portanto, não uma coisa, não um facto, não uma pressuposição, mas antes uma exigência de rearticulação que não desaparece nunca-mas que também nunca aparece?" (p. 185/186). Este tipo de humildade teórica seria, aliás, específica dos nossos tempos: "[a diferença sexual é] um momento particularmente denso de irresolução na linguagem, um momento que marca o horizonte contemporâneo da linguagem como nosso.” (p. 177). Quanto à humildade existencial, ela deve estar apoiada na consciência de que o processo de incorporação das normas culturais, nomeadamente de género, não é totalmente consciente e controlável: "Há sempre uma dimensão de nós mesmos e da nossa relação com os outros que não podemos conhecer, e este não-conhecer persiste connosco como uma condição da existência, orientada pelo que não conhecemos, e não podemos conhecer, e esta 'pulsão' (Trieb) é precisamente o que não é nem exclusivamente biológico nem cultural, mas sempre o lugar da sua densa convergência.” (p. 15). Esta fuga a si é vista pela autora como um lugar do êxtase: "E assim quando falamos sobre a minha sexualidade ou o meu género, como fazemos (e como temos que 
fazer), queremos dizer algo complicado com isso. Nada disso é exactamente uma possessão, mas ambos são entendidos como modos de ser despossuído, modos de ser para o outro ou, de facto, por meio de outro." (p. 19, itálicos da autora). "Ser ex-tático significa, literalmente, estar fora de si próprio [...]. [...] falo daqueles de nós que vivem de algumas maneiras para lá de nós próprios, quer seja numa paixão sexual, numa dor emocional, ou numa raiva política. Num certo sentido, o desafio é compreender que tipo de comunidade é composta por aqueles que estão para lá de si próprios” (p. 20, itálicos da autora). Trata-se, portanto, do êxtase como lugar politico, de formação de comunidade em geral.

Este lugar de humildade crítica, de humildade política, continua ser um lugar de trabalho da psicanálise: "O corpo é aquilo sobre o qual a linguagem tropeça, e o corpo carrega os seus próprios sinais, os seus próprios significantes, de formas que permanecem largamente inconscientes" (p.198). Portanto, todo o trabalho político de desconstrução da diferença sexual e rearticulação do humano acontece num quadro de forte indescernibilidade, teórica e viven- cial, entre o biológico e o cultural: "Não pretendo sugerir que sinais puramente culturais produzem um corpo material, mas somente que o corpo não se torna sexualmente legível sem esses sinais, e que esses sinais são irredutivelmente culturais e materiais ao mesmo tempo.” (p. 87).

Não existe, igualmente, nenhuma cristalização simbólica, nomeadamente da diferenciação sexual, que garanta um fundo imutável ao cultural: "[...] espero mostrar que a distinção entre lei simbólica e social não é enfim sustentável, que o próprio simbólico é a sedimentação de práticas sociais [...]" (p. 44). Todo o humano é portanto, re-articulável, lugar de luta política.

Esta obra é notável no esforço que faz de re-articulação das questões queer com a teoria crítica e a filosofia política, trazendo novos contributos a todas estas disciplinas. Como limite à pujança teórica de Butler pressinto apenas uma excessiva espiritualização, provavelmente resultado do seu judaísmo, que a impede de trabalhar no campo dos estudos visuais, o que lhe permitiria ultrapassar um excessivo dualismo e psicanalização da questão corpo-linguagem.

Anabela Rocha

\section{Louro, Guacira Lopes, Um Corpo Estranho - Ensaios sobre sexualidade e teoria queer. Belo Horizonte: Autêntica Editora, 2004, 92 p.}

Guacira Lopes Louro é uma autora com a qual os leitores portugueses interessados nas questões de género e da sexualidade poderão já estar familiarizados. Existe inclusivamente uma edição portuguesa de um trabalho recente - Currículo, género $e$ sexualidade (Porto: Porto Editora, 2000) que procura sintetizar e cruzar os principais interesses de pesquisa desta intelectual licenciada em História, doutorada em Educação e professora da Universidade Federal do Rio Grande do Sul. Guacira Lopes
Louro procurou desde cedo reflectir sobre a forma como o género e a sexualidade se cruzam com as políticas educativas, tendo em 1990 criado o GEERGE (Grupo de Estudos de Educação e Relação de Género), que se constitui desde então enquanto núcleo de investigação em torno destas temáticas.

Neste trabalho, reflectindo sobre o legado do pensamento feminista, a autora acabou por se aproximar das perspectivas pós-estruturalistas, no âmbito das quais se 
produziu a teoria queer, já no início dos anos 1990, sob a influência de autores como Michel Foucault, Jacques Lacan ou Jacques Derrida. Sob o olhar queer, mais do que pensar sobre a realidade, importa reflectir sobre os discursos produzidos acerca dela e operar uma desconstrução dos conceitos utilizados para a descrever. O objectivo será procurar expor o carácter compulsório que resulta da sua reprodução permanente, através de várias instâncias, e que se traduz na construção de uma lógica binária e assimétrica de sexos, géneros e sexualidades.

Parece tarefa impossível encontrar quem, após longos anos de carreira como cientista ou intelectual, não se comprometa de forma indelével com um património de ideias e conceitos ou escolas de pensamento. No trajecto da investigação, recorre-se a teorias, perfilham-se correntes, encontra-se conforto em conceitos e operações, e tudo se parece alicerçar ou mesmo refutar a partir de um inabalável, ainda que eventualmente moldável, conjunto de princípios orientadores. Para esta autora, contudo, este constitui um bom momento para questionar o inquestionado e distanciar-se dos modelos tradicionais de pensamento. Ao mesmo tempo, procura fazer um importante trabalho de tradução de textos e conceitos que de outra forma poderiam permanecer inacessíveis a um número considerável de leitores (também porque parece passar por aqui uma vontade de dessacralizar o próprio conhecimento).

Neste livro reúnem-se quatro pequenos ensaios - "Viajantes pós-modernos", "Uma política pós-identitária para a educação", "'Estranhar' o currículo" e "Marcas do corpo, marcas de poder". Trata-se maioritariamente de transcrições de palestras, onde algumas questões sobre o corpo e a sexualidade são repensadas à luz de um novo questionamento. Pensar 'queer' surge como uma forma de incluir a pluralidade de vivências de género e das sexualidades, realidade constatada pela própria autora na sua vivência pessoal e profissional. Ao atribuir-lhes um sentido dentro das possibilidades do conhecimento, permite-se que estas vivências adquiram um significado não só hermenêutico mas também político, designadamente se pensarmos nas potenciais implicações para o campo educativo. Por outro lado, há uma tentativa de superação da lógica binária de leitura da realidade, entendendo-se que, mais do que servir para compreender, esta tem estado ao serviço de um processo permanente de classificação e compartimentação da própria realidade, definindo fronteiras e hierarquias, através de dinâmicas de poder mais ou menos dissimuladas. $\mathrm{O}$ que importa neste processo será não tanto perceber qual a verdade, mas os mecanismos pelos quais esta verdade se estabelece enquanto tal.

O corpo, essa entidade que transporta as marcas identitárias (e, como tal, o produto de vários discursos), é também o lugar onde se observa a rebelião da diversidade, e onde se ensaiam tentativas de subversão das fronteiras de género. Um exemplo escolhido pela autora neste livro é a figura da drag queen, alguém que, na sua opinião, parodia a ideia de essência feminina através daquilo que Judith Butler designaria por uma elaborada performance de género que denuncia o seu carácter de construção (eloquente a expressão do homem que traz consigo na mala os acessórios para se transformar: "eu me monto e a drag baixa"). Parece fazer sentido incluir também neste âmbito de subversão inúmeros pequenos gestos diários de resistência dentro do regime de género e sexualidade dominante, como os que são facilmente observáveis diariamente no quotidiano de qualquer escola.

Somos todos queer? Em parte, se o padrão binário de masculinidade e feminilidade é 
uma prescrição de imagens e atitudes de que permanentemente nos desviamos, inconscientemente ou como gesto intencional de insubmissão. Por outro lado, as políticas identitárias feministas ou gays e lésbicas não podem ser enquadradas necessariamente num quadro de leitura queer; elas têm a seu encargo uma política de afirmação que se inscreve ainda na lógica de pensamento binário que domina a civilização ocidental desde a modernidade. Era na mesma lógica que Guacira Lopes Louro, numa palestra recente sobre Género e Cidadania na Faculdade de Psicologia e Ciências da Educação da Universidade do Porto, entre 9 e 10 de Junho de 2006, sublinhava a importância da sexualidade na definição da masculinidade (repare-se nas associação da impotência ao fim da masculinidade), agregada à homofobia e à misoginia, ao passo que nas mulheres a centralidade na definição do ser feminino parecia passar mais pela maternidade. Também poderemos estabelecer um paralelismo diferencial nas reacções sociais à "saída do armário" (a expressão que designa um homossexual que se assume publicamente enquanto tal): en- quanto os homens geralmente se interrogam sobre o tipo de performances sexuais, as mulheres tendem a verbalizar as presumidas implicações na possibilidade de maternidade ou paternidade. Nessa palestra, ressalvou ainda a necessidade de repensar as representações acerca dos argumentos essencialistas e construtivistas em relação ao género e à sexualidade. Sendo verdade que os primeiros são normalmente associados a correntes mais conservadoras, eles têm sido "repescados" para as políticas de identidade, tornando-se desta forma progressistas. Por outro lado, dizer que determinado conceito (por exemplo, a homossexualidade) é uma construção pode conduzir a um discurso do tipo corrector e "retrógrado" ("se conheço a causa, posso tentar eliminá-la”).

Em suma, estamos perante uma obra politicamente empenhada e cientificamente pertinente, para todos os que gostam de assumir a incerteza como o método de trabalho mais adequado para a compreensão da volatilidade e diversidade das realidades sociais.

Telmo Fernandes 